\title{
ANALISIS EFISIENSI PENGELOLAAN DANA BANTUAN OPERASIONAL SEKOLAH ( BOS ) SEBELUM DAN SESUDAH PENERAPAN SISTEM NON TUNAI DI SDIT DARUL FALAH NONGSA KOTA BATAM
}

\section{ANALYSIS OF THE EFFICIENCY OF THE MANAGEMENT OF SCHOLL OPERA- TIONAL ASSISTANCE FUNDS (BOS) BEFORE AND AFTER THE IMPLEMENTA- TION OF THE NON CASH SYSTEM AT SDIT DARUL FALAH NONGSA BATAM CITY}

\author{
Afrinanda ${ }^{1}$, Sri Mulyati ${ }^{2}$ \\ ${ }^{1}$ (Akuntansi, Ekonomi, Universitas Riau Kepulauan, Indonesia) \\ ${ }^{2}$ (Akuntansi, Ekonomi, Universitas Riau Kepulauan, Indonesia) \\ ,2 srimulyati.5587@gmail.com
}

\begin{abstract}
Abstrak
Penelitian ini bertujuan untuk mengetahui : (1) Bagaimana Analisis Efisiensi Pengelolaan Dana Bantuan Operasional Sekolah (BOS) Sebelum dan sesudah Penerapan Sistem Non Tunai pada SDIT Darul Falah Nongsa Kota Batam. Bentuk penelitian yang digunakan adalah kualitatif, pada tinjauan pustaka membahas teori penggunaan dan BOS sedangkan pada bab 3 metode penelitian yang digunakan adalah metode deskriptif dengan strategi tunggal terpancang. Sumber data yang digunakan terdiri dari informan, lokasi, peristiwa atau aktivitas, dokumen dan arsip. Teknik pengumpulan data yang digunakan adalah wawancara, observasi, dokumentasi, dan kuestioner. Pada bab 4 Hasil penelitian menunjukkan bahwa Analisis Efisiensi Pengelolaan Dana Bantuan Operasional Sekolah (BOS) Sebelum dan sesudah Penerapan Sistem Non Tunai di SDIT Darul Falah Nongsa Kota Batam meliputi : (1) perencanaan (2) pelaksanaan (3) pelaporan: hasil observasi tentang Bagaimanakah Analisis Efisiensi Pengelolaan Dana Bantuan Operasional Sekolah (BOS) Sebelum Penerapan Sistem Non Tunai pada SDIT Darul Falah Nongsa Kota Batam diperoleh data yang dilaksanakan 23 atau $(35,93 \%)$ dan yang tidak dilaksanakan 41 atau $(64,07 \%)$, bahwa pelaksanaan pengeolalaan dapat dikatakan kurang efisiens karena di dibawah $60 \%$. (2) Selanjutnya penulis menganalisa hasil hasil observasi tentang Bagaimanakah Analisis Efisiensi Pengelolaan Dana Bantuan Operasional Sekolah (BOS) sesudah Penerapan Sistem Non Tunai pada SDIT Darul Falah Nongsa Kota Batam diperoleh persentase akhir sebesar 50 atau $(78,13 \%)$ dan yang tidak dilaksanakan 14 atau $(21,87 \%)$ ini menandakan bahwa sistem nontunai lebih membantu dalam penggunaan anggaran dana BOS.
\end{abstract}

Kata Kunci ; Efisiensi, Pengelolaan dan Penerapan BOS, Penerapan Sistem Non Tunai 


\begin{abstract}
This research aims to acknowledge: (1) How the analysis of management efficiency of School Operational Assistance (BOS) Funds before and after implementing non-cash system in SDIT Darul Falah Nongsa Batam City. The research design applied is qualitative, the review of related literature explains the theory of utilizing the budget of BOS while on chapter 3, the research method applied is descriptive along with single-stick strategy. The research resources consist of informant, location, event or activity, document and archive. Data collection techniques applied are interview, observation, documentation, and questionnaire. On chapter 4, the result shows that the analysis of management efficiency of School Operational Assistance (BOS) Funds before and after implementing non-cash system in SDIT Darul Falah Nongsa Batam City such as; (1) planning, (2) implementing, (3) reporting: the observation result on how the analysis of management efficiency of School Operational Assistance (BOS) Funds before and after implementing non-cash system in SDIT Darul Falah Nongsa Batam City earned 23 or (35.93\%) data done and 41 or (64.07\%) data undone, states that the management was inefficient for earned under 60\%. then the researcher analyze on how the analysis of management efficiency of School Operational Assistance (BOS) Funds before and after implementing non-cash system in SDIT Darul Falah Nongsa Batam City obtained final percentage worth 50 or (78.13\%) and 14 or (21.87\%) data undone it indicates that non-cash system is more helpful in utilizing School Operational Assistance (BOS) Funds.
\end{abstract}

Keywords ; Efficiency, Management and Implementation of School Operational Assistance (BOS), Implementation of Non-Cash System

\section{PENDAHULUAN}

Pendidikan dipandang sebagai suatu sarana untuk meningkatkan mutu sumber daya manusia suatu bangsa. Pencapaian pendidikan suatu bangsa dapat dilihat dari kesesuaian antara tujuan dan keterlaksanaan pendidikan. Di Indonesia, menurut pasal 3 Undang-undang Nomor 20 Tahun 2003, tujuan pendidikan nasional adalah untuk mengembangkan potensi peserta didik agar menjadi manusia yang beriman dan bertaqwa kepada Tuhan Yang Maha Esa, berakhlak mulia, sehat, berilmu, cakap, kreatif, mandiri dan menjadi warga negara yang demokratis serta bertanggungjawab. Program Bantuan Operasional Sekolah (BOS) yang dimulai sejak bulan Juli 2005, telah berperan secara signifikan dalam percepatan pencapaian wajib belajar 9 (sembilan) tahun. Kementerian PendidikandanKebudayaan (Kemdikbud) mengeluarkan kebijakan baru terkait pengelolaan
Bantuan Operasional Sekolah (BOS). Kebijakan yang tertuang dalam Permendikbud nomor 8 tahun 2017 tertanggal 22 Februari 2017 ini dilampiri petunjuk teknis. Yang bertujuanmeningkatkan pertanggungjawaban belanja pendidikan, dengan pencatatan data transaksi pembayaran dalam system perbankan, melindungi dan memberikan rasa aman bagi pelaksana dan penggung jawab atas transaksi pembayaran. Selain itu juga bisa memperbaiki kualitas belanja pendidikan, melalui penyediaan data yangvalid untuk keperluan perencanaan, penggaran, dan pengendalian realisasi anggaran.

\section{Latar Belakang}

Salah satu sekolah yang menerima pendanaan BOS dan telah menerapkan sistem nontunai pada tahun 2017 adalah SDIT Darul Falah Nongsa Kota Batam. Dikarenakan jumlah peserta didiknya 881 siswa dan merupakan siswa terbanyak dibandingkan 
dengan Sekolah Dasar ( SD ) lainnya yang berda di Kecamatan Nongsa Kota Batam dengan kata lain sekolah tersebut juga mendapat dana Bantuan Oprasional Sekolah (BOS) yang lebih banyak yakni 881 siswa @Rp. 800.000,-/tahun sehingga sekolah tersebut dapat mewakili Sekolah Dasar ( SD ) yang telah menerapkan sistem nontunai dalam penelitian yang dilakukan oleh peneliti yakni analisis efisiensi pengelolaan dana Bantuan Oprasional Sekolah (BOS) sebelum dan sesudah penerapan sistem nontunai. Dikarenakan baru berlakunya kebijakan ini tentunya dikhawatirkan terdapat kendala yang dapat mempengaruhi penerapan sistem nontunai, terutama dalam pengelolaan dan Bantuan Oprasional Sekolah (BOS). Sehingga perlu dikaji kebijakan sistem nontunai yang diberlakukan oleh pemerintah dan baru diterapkan oleh instansi pendidikan salah satunya Sekolah Dasar. Sehingga peneliti membuat judul Analisis Efisiensi Pengelolaan Dana Bantuan Oprasionala Sekolah (BOS) Sebelum dan Sesudah Penerapan Sistem Nontunai di Sekolah Dasar Islam Terpadu ( SDIT ) Darul Falah Nongsa Kota Batam. Penelitian ini bertujuan untuk mengetahui lebih efisiensi mana sebelum atau sesudah penerapan sistem nontunai dalam pengelolaan dana Bantuan Operasional Sekolah (BOS) pada Sekolah Dasar Islam Terpadu ( SDIT ) Darul Falah Nongsa Kota Batam.

\section{Batasan Masalah}

Berdasarkan latar belakang yang dipaparkan di atas, maka diperlukan adanya pembatasan masalah sehingga penelitian yang dilakukan bisa lebih fokus dalam menggali masalah pada analisis efisiensi pengelolaan dana Bantuan Oprasional Sekolah ( BOS ) sebelum dan sesudah penerapan sistem nontunai di Sekolah Dasar Islam Terpadu ( SDIT ) Darul Falah Nongsa Kota Batam. yang difokuskan pada perbandingan tahun 2016 dan 2017.

\section{Rumusan Masalah}

Berdasarkan latar belakang dan batasan masalah yang telah di sampaikan di atas, maka rumusan masalah yang dapat di bentuk dari penelitian ini adalah "Bagaimana Efisiensi Pengelolaan Dana Bantuan Oprasional Sekolah (BOS) di Sekolah Dasar Islam Terpadu ( SDIT ) Darul Falah Nongsa Kota Batam. sebelum dan sesudah penerapan sistem nontunai ?".

\section{TINJAUAN PUSTAKA \\ Pengertian Analisis}

MenurutKamusBesar BahasaIndonesia(KBBI), pengertiananalisisadalah penyelidikan terhadap suatu peristiwa (karangan, perbuatan, dsb) untuk mengetahui keadaan yang sebenarnya (sebab-musabab, duduk perkaranya dsb) (KBBI, 2008: 58). Berdasarkan pengertian analisis tersebut yang dimaksud analisis pada penelitian ini adalah pengolahan suatu data yang didapat dari penelitian guna mengetahui keadaan yang sebenarnya yakni manakah yang lebih efisiein sebelum atau sesudah penerapan sistem nontunai pada pengelolaan dana Bantuan Operasional Sekolah (BOS) di Sekolah Dasar Isam Terpadu (SDIT) Darul Falah Nongsa Kota Batam.

\section{Pengelolaan Keuangan Sekolah}

Keuangan dan pembiayaan merupakan elemen yang menentukan dalam pelayanan pendidikan di sekolah. Dalam kaitannya dengan sistem manajemen, pembiayaan dan pengelolaan keuangan merupakan input dan proses untuk menghasilkan output berupa kualitas pelayanan pendidikan yang diselenggarakan oleh sekolah. Pembiayaan sekolah yang bersumber dari keuangan negara diatur dalam peraturan perundang-undangan. Undang-Undang Republik Indonesia Nomor 15 Tahun 2004 tentang Pemeriksaan Pengelolaan dan Tanggung Jawab Keuangan Negara Bab 1 Pasal 1Ayat 6 menjelaskan bahwa pengelolaan keuangan 
negara adalah keseluruhan kegiatan yang meliputi perencanaan, pelaksanaan, pengawasan, dan pertanggungjawaban oleh pejabat pengelola keuangan negara sesuai dengankedudukan dan kewenangannya. Berdasarkan pengertian tersebut, dapat disimpulkan bahwa pengelolaan keuangan sekolah merupakan keseluruhan aktivitas dalam mengatur keuangan sekolah dengan menerima dan membelanjakannya yang direncanakan, direalisasikan, diawasi, dan dipertanggungjawabkan oleh entitas sekolah dan pihak-pihak yang terkait di dalamnya guna menjalankan pelayanan pendidikan.

\section{Pengertian Efisiensi}

Efisiensi dalam pengelolaan dana pendidikan dilakukan dengan mengoptimalkan akses, mutu, relevansi, dan daya saing pelayanan pendidikan (Peraturan Pemerintah Republik Indonesia Nomor 48 Tahun 2008). Berdasarkan teori tersebut, peneliti menyimpulkan bahwa prinsip efisiensi dalam pengelolaan keuangan sekolah merupakan pemberdayaan sumber daya uang sekolah dalam mencapai optimalisasi akses, mutu, relevansi, dan daya saing pelayanan pendidikan.

\section{Mekanisme Pembayaran Non Tunai}

Kementerian Pendidikan dan Kebudayaan (Kemdikbud) mengeluarkan kebijakan baru terkait pengelolaan Bantuan Operasional Sekolah (BOS). Kebijakan yang tertuang dalam Permendikbud nomor 8 tahun 2017 tertanggal 22 Februari 2017 ini dilampiri petunjuk teknis (Juknis) BOS yang berbeda dengan Juknis dalam Permendikbud nomor 80 tahun 2015. Salah satu kebijakan tersebut yakni mekanisme pembayaran nontunai. Menindaklanjuti hal tersebut, Kementerian Pendidikandan Kebudayaan telah merintis implementasi pembayaran non tunai, salah satunya dalam pelaksanaan belanja program BOS yang mendorong pembayaran non tunai dan belanja melalui mekanisme belanja/pengadaan e-purchasing. Sebagai perwujudan atas komitmen yang lebih besar, Kementerian Pendidikan dan Kebudayaan mengembangkan mekanisme pembayaran secara non tunai lebih jauh, khususnya di belanja BOS. Kebijakan pembayaran non tunai BOS ini sejalan dengan arah kebijakan Kementerian Pendidikan dan Kebudayaan dalam penguatan tata kelola keuangan pendidikan, yaitu meningkatkan transparansi dan akuntabilitas belanja pendidikan, sehingga mendorong perbaikan kualitas belanja pendidikan.

\section{Pengertian BOS}

Bantuan Oprasional Sekolah (BOS) adalah program pemerintah yang pada dasarnya untuk menyediakan pendanaan biaya oprasional non personalia bagi sekolah . Menurut Peraturan Pemerintah Nomor 48 Tahun 2008 tentang pendanaan Pendidikan, biaya non personalia adalah biaya untuk bahan atau peralatan pendidikan habis pakai, dan biaya tak langsung berupa daya, air, jasa telekomunikasi, pemeliharaan sarana dan prasarana, uang lembur, transportasi, konsumsi, pajak dan lain-lain. Namun demikian bebrapa jenis pembiayaan investasi dan personalia yang boleh dibiayai dengan dana BOS.

\section{Penelitian Terdahulu}

Penelitian yang dilakukan oleh Ristya Dwi Anggraini (2013) yangberhubunga dengan Transparansi, Partisipasi, Akuntabilitas Pengelolaan Anggaran Dana BOS dalam Program RKAS di SDN Pacarkeling VIII Surabaya menyatakan sangat transparan. Pada penelitian Hani Fitria (2014) dengan judul Efektivitas Pengelolaan Program Bantuan Operasional Sekolah (BOS) (Studi pada SMK PGRI Pandaan), menunjukkan hasil yang efektif. Penelitian yang diakukan 
oleh Kusno,asuyah Suib, Wahyudi (2012) dengan judul Pengelolaan Dana Bantuan Oprasional Sekolah (BOS) Di Sekolah Dasar Negeri 01 Muara Pawan Kabupaten

Ketapang, menyimpulkan telah dilaksanakan dengan baik oleh Tim Manajemen BOS sekolah dengan melakukan kegiatan identifikasi kebutuhan yang dilaksanakan melalui kegiatan evaluasi diri sekolah dan analisis SWOT.

Untuk penelitian yang dilakukan oleh Erwantosi (2010) dengan judul Analisis Efektifitas, Akuntabilitas dan Transparansi Bantuan Oprasional Sekolah pada Sekolah Menengah Pertama di Kota Padang menunjukkan hasilnya belum efektif dilihat dari tujuan dan sasaran program yang belum sesuai dengan standar yang telah ditentukan, akuntabilitas pengelolaan BOS belum berjalan dengan baik dilihat dari penyusunan RAPBS dan penggunaan dana BOS tidak melibatkan guru dan komite sekolah sebagai alat kontrol, transparansi dalam pengelolaan dana BOS terlihat masih sangat lemah dari kebijakan pengelolaan program dan penggunaan dana belum diumumkan secara keseluruhan dan mekanisme sistem kontrol program BOS yang berjalan tidak efektif.

\section{METODOLOGI PENELITIAN Objek}

Objek penelitian yang ada dalam penelitian adalah pengelolaan dana Bantuan Oprasional Sekolah (BOS) Sekolah Dasar Islam Terpadu (SDIT) Darul Falah yang beralamat di Jl. Hang Tuah Batu Besar Kecamatan Nongsa Kota Batam berdasarkan penerapan sebelum dan sesudah sistem non tunai.

\section{Waktu Penelitian}

01 November 2017 - 07 Maret 2018

\section{Jenis Penelitian}

Jenis Penelitian yang digunakan dalam penelitian ini adalah dengan menggunakan pendekatan kualitatif dengan metode studi kasus. Dimana data yang terkumpul akan disusun, dipelajari kemudian dianalisis atau dievaluasi. Penelitian kualitatif tersebut adalah penelitian tentang riset yang sifatnya deskriptif.

\section{Jenis Data}

a. Data Primer

b. Data Sekunder

\section{Teknik Pengumpulan Data}
a. Survey Pendahuluan
b. Penelitian Kepustakaan (library research)
c. Wawancara
d. Observasi
e. Dokumentasi

\section{Prosedur Penelitian}

a. Perencanaan

b. Pelaksanaan

c. Pelaporan

\section{Teknik Analisis Data}

Adapun teknik Analisa data yang digunanakan dalam penelitian ini adalah analisa komparatif merupakan jenis penelitian deskriptif yang berusaha mencari jawaban secara mendasar mengenai sebab-akibat, dengan menganalisis faktor-faktor penyebab terjadinya maupun munculnya suatu fenomena atau kejadian tertentu. Penelitian komperatif menurut ( Sugiyono 2012:92 ) yaitu "penelitian yang membandingkan keberadaan satu variabel atau lebih pada dua atau sampel yang berbeda, atau pada waktu yang berbeda". Melihat dari analisis data ini menggunakan teknik analisis diskriftif kualitatif dengan persentase, kemudian dianalisis dengan menggunakan tehnik ini bertujuan untuk mengetahui kate- 
gori bagaimana Analisi Efisiensi Pengelolaan Dana Bantuan Operasional Sekolah (BOS) Sebelum dan Sesudah Penerapan Sistem Non Tunai di SDIT Darul Falah Nongsa Kota Batam. Rumus yang digunakan untuk menganalisis yaitu :

$\mathrm{F} / \mathrm{N} \times 100=\mathrm{P}$

$\mathrm{F}$ : Frekwensi

$\mathrm{N}$ : Nilai Keseluruhan

$\mathrm{P}$ : Persentase

Kemudian hasil dari pengelolaan rumus di atas akan dibandingaknan dengan nilai Indikator di Bawah ini :

$81 \%$ sampai $100 \%$ disimpulkan, sangat optimal

$61 \%$ sampai $80 \%$ disimpulkan, optimal $41 \%$ sampai $60 \%$ disimpulkan, kurang optimal

$21 \%$ sampai $40 \%$ disimpulkan, tidak optimal

0\% sampai $20 \%$ disimpulkan, sangat tidak optimal.

HASIL PENELITIAN DAN PEMBAHASAN

\section{Sejarah Berdirinya SDIT Darul Falah}

SDIT Darul Falah adalah SD yang bernaung di bawah Yayasan Pondok Pesantren Darul Falah yang Didirikan pada tahun 1987, dan pada saat itu hanya MTs Darul Falah saja yang baru didirikan, melihat banyaknya kemajuan setiap tahun di kota Batam, barulah 15 tahun kemudian atau tepatnya pada tahun 2002 SDIT Darul Falah didirikan, seiring berkembangnya kota $\mathrm{Ba}-$ tam lantas membuat sekolah ini banyak kemajuan yang dimiliki dan membuat SDIT ini menjadi salah satu sekolah favorit di kecamatan Nongsa, siswanyapun beraneka ragam mulai dari kelurahan tempat mereka berdiri yaitu Batu Besar maupun kelurahan tetangga seperti Sambau, Belian.

\section{Penyajian Data}

Sebagaimana telah dijelaskan pada bab sebelumnya bahwa untuk mengumpulkan data tentang Analisis Efisiensi Pengelolaan Dana Bantuan Operasional Sekolah (BOS) Sebelum Dan Sesudah Penerapan System Non Tunai di SDIT Darul Falah Nongsa Kota Batam. Berikut ini akan penulis sajikan data-data hasil olahan yang penulis sajikan dalam bentuk tabel-tabel.

1. Bagaimanana Analisis Efisiensi Pengelolaan Dana Bantuan Operasional Sekolah (BOS) Sebelum Penerapan System Non Tunai di SDIT Darul Falah Nongsa Kota. Maka peneliti menjelaskan sebagai sebagai berikut ini :

Tabel 1

Tabel Hasil Persentase Wawancara

\begin{tabular}{|l|c|l|l|l|}
\hline \multirow{2}{*}{ WAWANCARA } & \multicolumn{4}{|c|}{ HASIL } \\
\cline { 2 - 4 } & \multicolumn{2}{|c|}{ YA } & \multicolumn{2}{c|}{ TIDAK } \\
\hline \multirow{2}{*}{ F } & \multicolumn{1}{|c|}{ P } & \multirow{2}{*}{ F } & \multicolumn{1}{c|}{ P } \\
& & \multicolumn{1}{|c|}{$\%$} & & \multicolumn{1}{c|}{$\%$} \\
\hline 4.3 & 3 & $37.5 \%$ & 5 & $62.5 \%$ \\
\hline 4.4 & 1 & $12.5 \%$ & 7 & $87.5 \%$ \\
\hline 4.5 & 5 & $62.5 \%$ & 3 & $37.5 \%$ \\
\hline 4.6 & 2 & $25 \%$ & 6 & $75 \%$ \\
\hline 4.7 & 4 & $50 \%$ & 4 & $50 \%$ \\
\hline 4.8 & 2 & $25 \%$ & 6 & $75 \%$ \\
\hline 4.9 & 3 & $37.5 \%$ & 5 & $62.5 \%$ \\
\hline 4.10 & 3 & $37.5 \%$ & 5 & $62.5 \%$ \\
\hline IV. 11 Jumlah & 2 & 35,93 & 4 & 64.07 \\
& 3 & $\%$ & 1 & $\%$ \\
\hline
\end{tabular}

Jika penulis menganalisa dari hasil tabel 4.11 hasil wawancara tentang Analisis Efisiensi Pengelolaan Dana Bantuan Operasional Sekolah (BOS) Sebelum Penerapan Sistem Non Tunai di SDIT Darul Falah Nongsa Kota Batam diperoleh data yang dilaksanakan 23 atau $(35,93 \%)$ dan yang 
tidak dilaksanakan 41 atau $(64,07 \%)$, maka untuk mengetahui efisiensinya digunakan rumusan sebagaimana pada bab 3 yaitu bahwa Efisiensi Pengelolaan Dana Bantuan Operasional Sekolah (BOS) Sebelum Penerapan Sistem Non Tunai tidak optimal karena di dibawah $61 \%$.

2. Bagaimanana Analisis Efisiensi Pengelolaan Dana Bantuan Operasional Sekolah (BOS) Sesudah Penerapan Sistem Non Tunai di SDIT Darul Falah Nongsa Kota. Maka peneliti menjelaskan sebagai sebagai berikut ini :

TabeL 2

Tabel Hasil Persentase Wawancara

\begin{tabular}{|l|l|l|l|l|}
\hline \multirow{2}{*}{ WAWANCARA } & \multicolumn{4}{|c|}{ HASIL } \\
\cline { 2 - 5 } & \multirow{2}{*}{ F } & \multicolumn{2}{|c|}{ P } & \multicolumn{2}{c|}{ TIDAK } \\
\hline & \multirow{2}{*}{} & \multicolumn{1}{|c|}{ P } & \multicolumn{1}{c|}{$\%$} \\
\hline 4.12 & 7 & $87.5 \%$ & 1 & $12.5 \%$ \\
\hline 4.13 & 7 & $87.5 \%$ & 1 & $12.5 \%$ \\
\hline 4.14 & 6 & $75 \%$ & 2 & $25 \%$ \\
\hline 4.15 & 6 & $75 \%$ & 2 & $25 \%$ \\
\hline 4.16 & 6 & $75 \%$ & 2 & $25 \%$ \\
\hline 4.17 & 6 & $75 \%$ & 2 & $25 \%$ \\
\hline 4.18 & 6 & $75 \%$ & 2 & $25 \%$ \\
\hline 4.19 & 6 & $75 \%$ & 2 & $25 \%$ \\
\hline 4.20 Jumlah & 5 & 18.13 & 1 & 21.87 \\
& 0 & $\%$ & 4 & $\%$ \\
\hline
\end{tabular}

Jika penulis menganalisa dari hasil tabel 4.20 hasil wawancara tentang Analisis Efisiensi Pengelolaan Dana Bantuan Operasional Sekolah (BOS) Sesudah Penerapan Sistem Non Tunai di SDIT Darul Falah Nongsa Kota Batam diperoleh data yang dilaksanakan 50 atau $(78,13 \%)$ dan yang tidak dilaksanakan 14 atau $(21,87 \%)$, maka untuk mengetahui efisiensinya digunakan rumusan sebagaimana pada bab 3 yaitu bahwa Efisiensi Pengelolaan Dana Bantuan Operasional Sekolah (BOS) Sesudah Penerapan Sistem Non Tunai dikatakan optimal karena di atas $61 \%$.

\section{Analisis Data}

Jika penulis menganalisa dari tabel 4.3 - 4.10 hasil wawancara tentang Bagaimanakah Analisis Efisiensi Pengelolaan Dana Bantuan Operasional Sekolah (BOS) Sebelum Penerapan Sistem Non Tunai di SDIT Darul Falah Nongsa Kota Batam diperoleh data yang dilaksanakan 23 atau $(35,93 \%)$ dan yang tidak dilaksanakan 41 atau $(64,07 \%)$, bahwa pelaksanaan pengeolalaan dapat dikatakan kurang efisiensi karena di dibawah $60 \%$.

Selanjutnya penulis menganalisa hasil dari Analisis Efisiensi Pengelolaan Dana Bantuan Operasional Sekolah (BOS) Sesudah Penerapan Sistem Non Tunai di SDIT Darul Falah Nongsa Kota Batam dari table 4.12 4.20 diperoleh persentase akhir sebesar 50 atau $(78,13 \%)$ dan yang tidak dilaksanakan 14 atau $(21,87 \%)$ dapat dikatakan bahwa efisiensi karena sudah optimal di atas $61 \%$.

\section{KESIMPULAN DAN SARAN Kesimpulan}

Penelitian ini merupakan penelitian kualitatif menggunakan delapan kali wawancara dan melakukan observasi mengenai sistem non unai, dimana yang peneliti wawancara adalah kepala sekolah SDIT Darul Falah, setelah hasil didapat kemudian dianalisa sesuai dengan metode yang penulis gunakan pada teori bab III skripsi ini. Berdasarkan hasil penelitian tentang Analisis Efisiensi Pengelolaan Dana Bantuan Operasional Sekolah (BOS) Sebelum dan sesudah Penerapan Sistem Non Tunai di SDIT Darul Falah Nongsa Kota Batam disimpulkan bahwasanya analisa tabel 4..34.10 pada hasil wawancara menjelaskan 
bagaimanakah Analisis Efisiensi Pengelolaan Dana Bantuan Operasional Sekolah (BOS) Sebelum Penerapan Sistem Non Tunai di SDIT Darul Falah Nongsa Kota Batam diperoleh data yang dilaksanakan 23 atau $(35,93 \%)$ dan yang tidak dilaksanakan 41 atau (64,07\%), bahwa pelaksanaan pengeolalaan dapat dikatakan kurang optimal karena di dibawah $60 \%$.

Analisis Efisiensi Pengelolaan Dana

Bantuan Operasional Sekolah (BOS) Sesudah Penerapan Sistem Non Tunai di SDIT Darul Falah Nongsa Kota Batam diperoleh hasil persentase akhir sebesar 50 atau $(78,13 \%)$ dan yang tidak dilaksanakan 14 atau $(21,87 \%)$, bahwa pelaksanaan pengeolalaan dapat dikatakan optimal karena di atas $60 \%$, ini menandakan bahwa sistem dengan non tunai sangat efisiensi yang dapat menghindari dari resiko kesalahan dalam penggunaan anggaran dan BOS.

\section{Saran}

Dalam pelaksanaan, perlu adanya evaluasi dari yayasan bagaimana kepala sekolah dalam melaksanakan tugasnya. Adanya laporan pengelolaan yang dibuat kepala sekolah sebagai laporan kepada yayasan sebagai Lembaga yang menaungi SDIT Darul Falah. Diharapkan semua pihak, baik itu yayasan, guru, maupun komite ikut andil dalam membantu kinerja kepala sekolah. Untuk peneliti selanjutnya diharapkan agar dapat melakukan observasi dan wawancara dengan narasumber yang lebih banyak, agar dapat menghasilkan informasi yang lebih akurat.

\section{DAFTAR PUSTAKA}

Badan Pengambangan dan Pembinaan Bahasa. (2018).Kamus

Besar Bahasa Indonesia versi dalam jaringan.

Melalui kbbi.wed.id/ diakses pada 08 Desember 2017 pada pukul 12.55.
Dwi, Anggraini Ristya. "Transparansi, Partisipasi, Akuntabilitas Pengelolaan Anggaran Dana BOS dalam Program RKAS di SDN Pacarkeling VIII Surabaya," Jurnal Kebijakan dan Manajemen Publik, Vol.1, No. 2, Mei- Agustus 2013.

Erwantosi. (2010). Analisis Efektifitas, Akuntabilitas dan Transparasi Bantuan Operasional Sekolah pada Sekolah Menengah Pertama di Kota Padang. Tesis Universitas Andalas.

Hani Fitria. (2014).Efektivitas Pengelolaan Program Bantuan Operasional Sekolah (BOS) (Studi Pada SMK PGRI Pandaan). Skripsi Universitas Negeri Surabaya.

Kusno, Masluyah Suib, Wahyudi. (2012). Pengelolaan Dana Bantuan Oprasional Sekolah (BOS) Di Sekolah Dasar Negeri 01 Muara Pawan Kabupaten Ketapang.

Peraturan Pemrintah (PP) Republik Indonesia nomor 8 tahun 2017 tertanggal 22 Februari 2017.

Peraturan Pemerintah Republik Indonesia Nomor 48 Tahun 2008 tentang Pendanaan Pendidikan.

Sugiyono. 2012 : 92. "penelitian yang membandingkan keberadaan satu variabel atau lebih pada dua atau sampel yang berbeda, atau pada waktu yang berbeda". Undang-Undang Republik Indonesia Nomor 15 Tahun 2004 tentang Pemeriksaan Pengelolaan dan Tanggung Jawab Keuangan Negara. 


\section{Undang-Undang Republik Indonesia Nomor 20 Tahun 2003 tentang Sistem Pendidikan Nasional.}

